\section{RMD Open}

Rheumatic \&

Musculoskeletal Diseases

\title{
Window of opportunity in rheumatoid arthritis - definitions and supporting evidence: from old to new perspectives
}

\author{
Leonie E Burgers, ${ }^{1}$ Karim Raza, ${ }^{2,3}$ Annette $\mathrm{H}$ van der Helm - van Mil ${ }^{\odot 1,4}$
}

To cite: Burgers LE, Raza K, van der Helm - van Mil AH. Window of opportunity in rheumatoid arthritis definitions and supporting evidence: from old to new perspectives. RMD Open 2019;5:e000870. doi:10.1136/ rmdopen-2018-000870

- Prepublication history and additional material for this paper are available online. To view these files, please visit the journal online (http://dx.doi. org/10.1136/rmdopen-2018000870).

Received 27 November 2018 Revised 4 March 2019 Accepted 5 March 2019

\section{Check for updates}

C) Author(s) (or their employer(s)) 2019. Re-use permitted under CC BY-NC. No commercial re-use. See rights and permissions. Published by BMJ.

${ }^{1}$ Department of Rheumatology, Leids Universitair Medisch Centrum, Leiden, The Netherlands

${ }^{2}$ Immunity and Infection, University of Birmingham, Birmingham, UK

${ }^{3}$ Rheumatology, Sandwell and West Birmingham Hospitals NHS Trust, Birmingham, UK ${ }^{4}$ Department of Rheumatology, Erasmus Medical Center, Rotterdam, The Netherlands

Correspondence to Professor Annette H van der Helm - van Mil;

a.h.m.van_der_helm@lumc.n|

\section{ABSTRACT}

The therapeutic window of opportunity in rheumatoid arthritis (RA) is often referred to. However, some have questioned whether such a period, in which the disease is more susceptible to disease-modifying treatment, really exists. Observational studies are most frequently referenced as supporting evidence, but results of such studies are subject to confounding. In addition formal consensus on the definition of the term has never been reached. We first reviewed the literature to establish if there is agreement on the concept of the window of opportunity in terms of its time period and the outcomes influenced. Second, a systemic literature search was performed on the evidence of the benefit of early versus delayed treatment as provided by randomised clinical trials. We observed that the concept of the window of opportunity has changed with respect to timing and outcome since its first description 25 years ago. There is an 'old definition' pointing to the first 2 years after diagnosis with increased potential for disease-modifying treatment to prevent severe radiographic damage and disability. Strong evidence supports this concept. A 'new definition' presumes a therapeutic window in a pre-RA phase in which the biologic processes could be halted and RA development prevented by very early treatment. This definition is not supported by evidence, although is less well studied in trials. Some suggestions for future research in this area are made.

\section{INTRODUCTION}

Outcomes for patients with rheumatoid arthritis (RA) have changed dramatically over the last 25 years. These advances have been attributed to the development and use of novel disease-modifying drugs (including biologics), treat-to-target strategies resulting in better control of disease activity, and the earlier initiation of disease-modifying treatments.

The rationale behind earlier treatment initiation is that it allows modulation of biologic processes while they are in a less mature and more reversible stage. ${ }^{12}$ This stage has previously been referred to as a therapeutic window of opportunity. ${ }^{1}{ }^{2}$ Nevertheless, varying definitions exist of the window of opportunity. The first mention of a window of opportunity in RA was in 1992 by Dawes and Symmons. ${ }^{3}$ At that time it was described as 'a small window of opportunity (2 years) in which to get the disease in remission before irreversible damage is done to joints'. Since then, the term 'window of opportunity' has been increasingly used in the rheumatological literature. However some have questioned whether such a period, in which the disease is more susceptible to disease-modifying treatment, really exists, and formal consensus on the definition of the term has never been reached.

In this Viewpoint we set out to propose a definition of the 'window of opportunity' based on data obtained from the literature. First we questioned whether or not the term 'window of opportunity' has been used in a consistent way since 1992. To address this, we reviewed the literature on articles that used the term 'window of opportunity' in the context of RA. We explored whether there was consensus in terms of the long-term outcomes that were considered to benefit from early treatment, as well as on the time period, expressed as the symptom or disease duration, that was proposed to cover the window of opportunity. Second, we determined the level of evidence for the association between the timing of intervention and the disease outcomes that were identified in the first part. Although a previous literature review concluded that prolonged symptom duration at treatment initiation in patients with classified RA is associated with more radiographic progression and a lower chance of achieving disease-modifying antirheumatic drug (DMARD)-free sustained remission (findings that may support the presence of a window of opportunity), this conclusion was largely driven by findings from observational cohort studies. ${ }^{4}$ In such cohort studies, the timing of DMARD 
start was not determined by randomisation. Therefore, a combination of patient and environmental characteristics, both known and unknown, may have influenced when DMARD therapy was initiated. Because of this, the causality of the associations with symptom duration is susceptible to confounding and reverse causation bias. Randomised controlled trials (RCTs) do not have this drawback. Therefore we systemically searched the literature on RCTs evaluating the effect of early (vs delayed, thus initial treatment with placebo) treatment with DMARDs. We exclusively concentrated the present literature search on findings from RCTs. We studied RCTs performed in patients with classified RA. Moreover, as the field of RA has moved towards identifying patients in earlier disease phases, in the current search we also performed RCTs performed in patients with undifferentiated arthritis (UA) and arthralgia without clinically apparent arthritis.

\section{Is there consensus on how to define the window of opportunity?}

A generic search on PubMed on ('( (rheumatoid arthritis) AND window of opportunity)') resulted in 89 articles; evaluation of full texts revealed 75 relevant articles (both original articles as well as other types of papers) on the window of opportunity.

\section{Timing of the window of opportunity}

In 37 of $75(49 \%)$ articles, no exact duration of the window of opportunity was included in the description; these articles often used general terms, like 'early'. Other articles did not include a chronological period, but a disease phase, such as the phase preceding radiographic damage (two articles $)^{56}$ or preceding RA development (five articles). ${ }^{7-11}$ With regard to studies that mentioned a specific time duration, some studies described the window to encompass the first 2 years after disease onset (nine articles). ${ }^{361012-17}$ As illustrated in figure 1A, these articles were mainly written in the 1990s and early 2000 s. The most frequently used time description period encompassed the first 12 weeks or 3 months after symptom onset (19 articles) ${ }^{14} 6101218-31$; the majority of these papers were published after 2010 (figure 1A). Hence, as time has passed, the window of opportunity has been assumed to be confined to a shorter period occurring in an earlier phase of the disease.

\section{Long-term outcomes}

Twenty-six out of 75 articles (35\%) used general terms with regard to the long-term outcomes that could be achieved when treatment is started within the window of opportunity (eg, 'sustained clinical benefits' or 'better outcomes'). The most frequently mentioned specific outcome was prevention or slowing of radiographic damage (40 articles). $.^{3-6} \quad 10 \quad 12-18 \quad 22 \quad 24 \quad 26 \quad 30-54$ The second most frequently mentioned outcome was remission, either clinical remission, Disease Activity Score (DAS) remission or drug-free remission (22

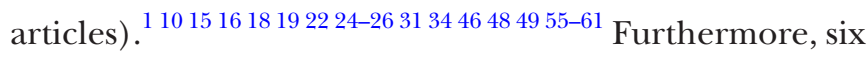
articles mentioned that treatment within the window of

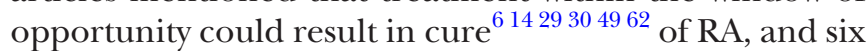
articles even mentioned prevention of RA as the outcome of treatment within the window of opportunity. ${ }^{7-1161}$ As shown in figure $1 \mathrm{~B}$, these latter outcomes were present in more recent descriptions of the window of opportunity.

In conclusion, the definition of the window of opportunity as was retrieved from the literature revealed that the concept has changed over time. Whereas it was previously defined as a treatment period in the first 2 years after disease onset in which joint damage could be halted ('old definition'), it is increasingly considered to represent a period before the diagnosis is established in which treatment could potentially prevent RA development ('new definition').

\section{EVIDENCE OBTAINED FROM RANDOMISED CLINICAL TRIALS IN FAVOUR OF EARLY TREATMENT}

Next, in order to determine the level of evidence of the associations that are the basis of these definitions, we systematically assessed databases (PubMed, Medline, Embase) for RCTs that compared early versus delayed treatment with DMARDs in different disease phases (RA, UA and arthralgia preceding clinical arthritis) (see online supplementary methods for used terms). Patients in all these phases required to be DMARD-naïve at trial entry. Delayed treatment was defined as absence of DMARD use for a certain period. Hence an early treatment group was compared with a group that only used placebo (please see online supplementary methods for the inclusion and exclusion criteria that were used). The quality of all included studies was determined using a 15-point quality list that was adapted from lists previously used in systematic reviews ${ }^{463}$ (online supplementary tables 1 and 2). As previously, ${ }^{4}$ studies with a quality score $\geq 75 \%$ were considered high-quality studies. Due to heterogeneity in study designs, pooled effect estimates were not calculated, but a best-evidence synthesis was performed, based on the method described by the Cochrane Collaboration Back Review Group (online supplementary table 3). ${ }^{64}$

\section{RCTs in early RA}

First we searched the literature for RCTs in early RA (disease duration <2 years) comparing early DMARD initiation with non-DMARD therapy or delayed DMARD therapy. A total of 11 trials were identified, all published between 1988 and 2003 (table 1); 9 trials assessed the outcome radiographic damage ${ }^{1765-72}$ and 8 functional disability. ${ }^{176569-74}$

\section{Radiographic damage in RA}

All nine RCTs included DMARD-naive patients with a disease duration of $<2$ years who fulfilled the classification criteria for RA (either the 1958 or the 1987 criteria) (table 1). Follow-up ranged between 6 months and 5 years. Different DMARDs (gold, sulfasalazine, hydroxychloroquine, methotrexate [MTX] and prednisone) 
A

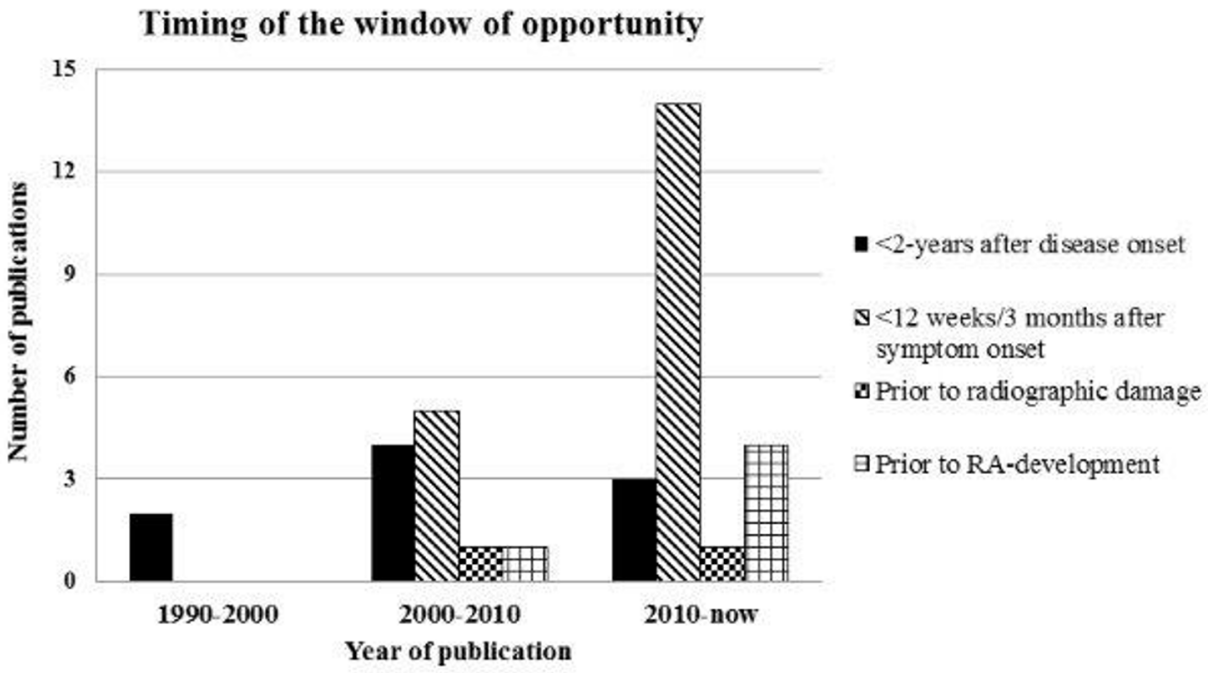

B

Outcome of treating within the window of opportunity

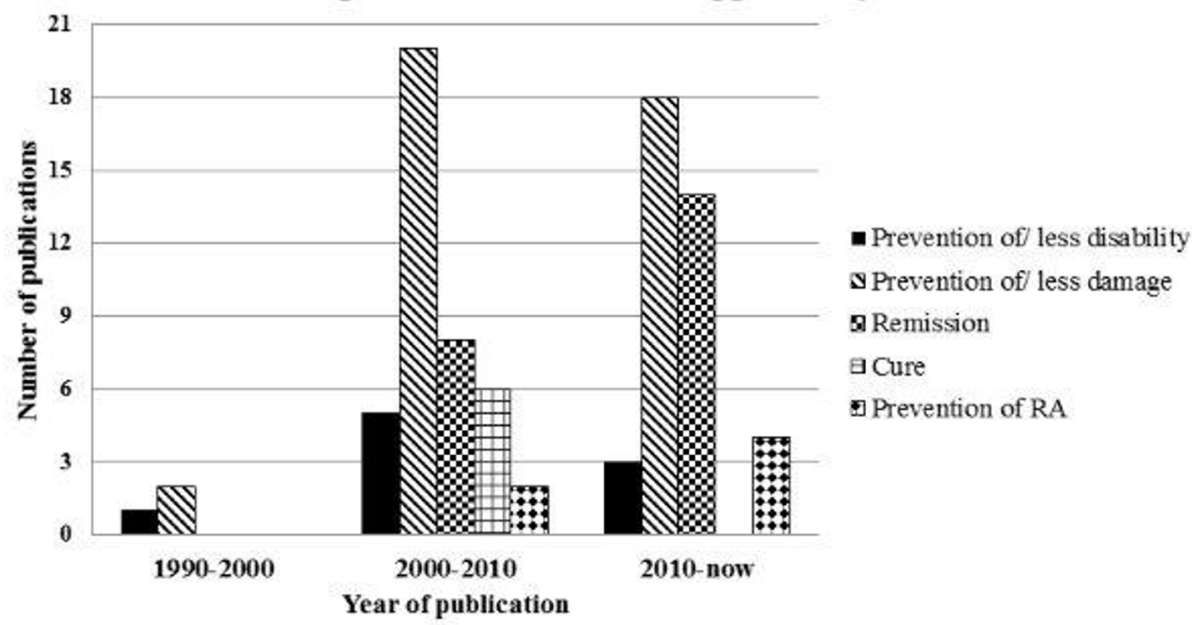

Figure 1 Results from literature search on the concept of the window of opportunity in rheumatoid arthritis (RA) with regard to its time period (A) and long-term outcome that is influenced (B). The bars correspond to the number of times a specific time period or long-term outcome was mentioned in the 75 articles mentioning the window of opportunity in RA. As some articles mentioned more than one time period or outcome, and other papers did not mention a specific time period or outcome at all, the numbers in the bars do not necessarily add up to 75 .

and different measures for radiographic damage (Larsen score, [modified] Sharp score, presence of erosions and erosion area) were used. A significant benefit for the early DMARD arm with regard to radiographic damage was shown in five RCTs, ${ }^{1765} 687071$ of which three were of high quality ${ }^{176570}$ (two of these reported on the same trial). ${ }^{1765}$ Three RCTs showed a statistically non-significant benefit for the early DMARD arm, ${ }^{666769}$ and in one trial there was no effect. ${ }^{72}$ Since there were consistent findings in multiple high-quality RCTs (as well as in low-quality RCTs), there is strong evidence to conclude that early DMARD initiation results in better radiographic outcomes (figure 2). Importantly, earlier treatment resulted in lower absolute levels of joint damage and in lower progression rates (ie, less steep progression curves over time). ${ }^{176570}$ Especially the latter finding of less rapid rise over time is suggestive of true disease modification. With respect to timelines, the early treatment group in these trials started DMARDs $~ 6-12$ months earlier than the delayed group (table 1 ).

\section{Functional disability}

All eight RCTs that measured functional disability as outcome (table 1) included DMARD-naïve patients fulfilling the classification criteria for RA (1958 or 1987) with a disease duration $<2$ years. Follow-up ranged between 36 weeks and 5 years. Different measures of functional disability were used (Health Assessment Questionnaire, Keitel Functional Index, Arthritis Impact Measurement Scales and McMaster-Toronto Arthritis Patient Preference Disability Questionnaire). Seven of the RCTs were of high quality. However, four different study populations were described, as three articles were long-term follow-up papers of previously reported study populations. ${ }^{17} 7274$ Four out of seven high-quality studies revealed a significant benefit for the early DMARD arm, ${ }^{17656973}$ of which 


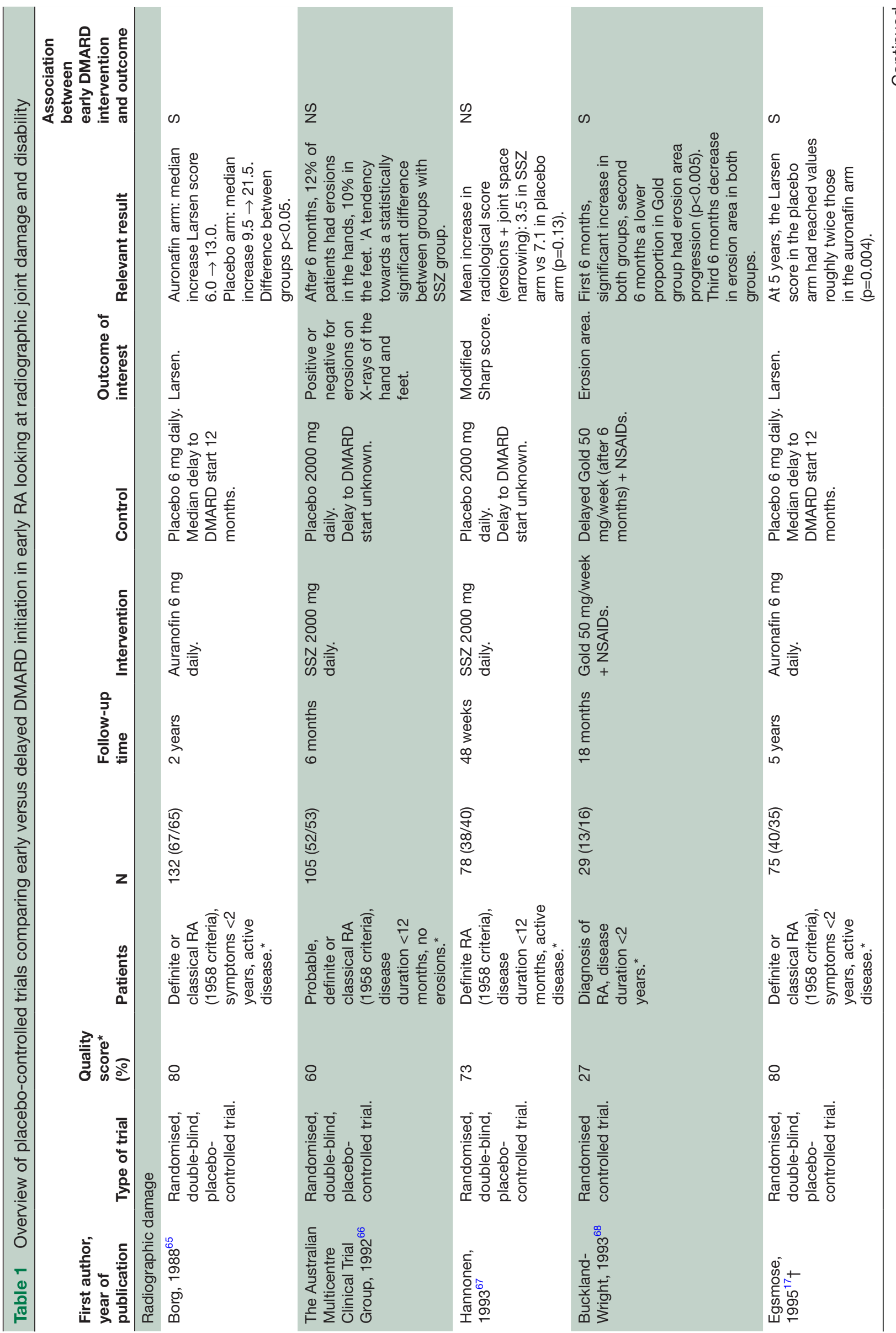



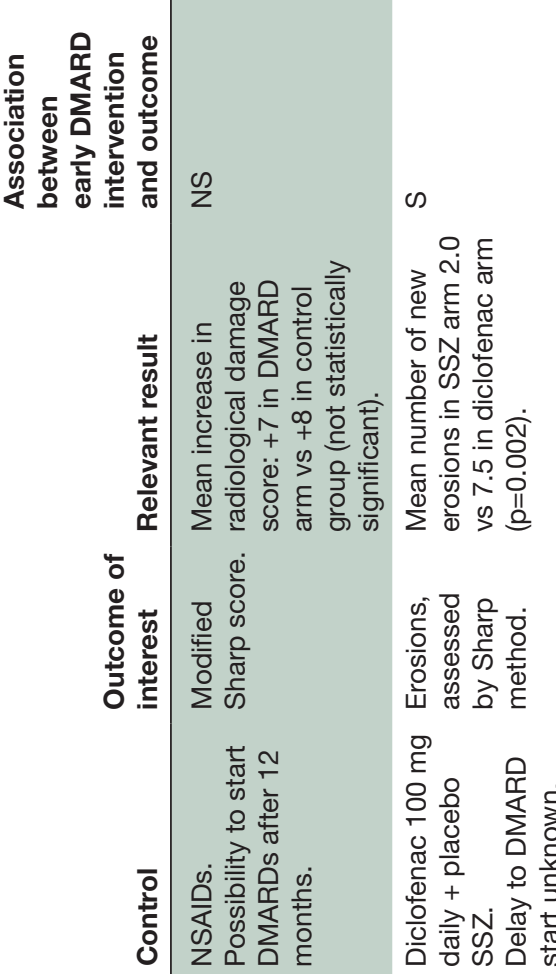

일

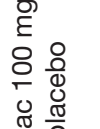

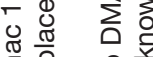

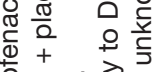

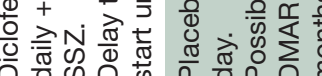

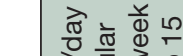

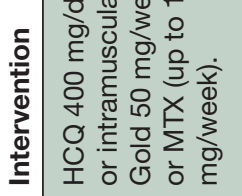

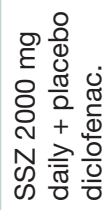

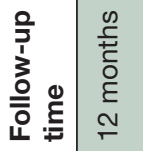

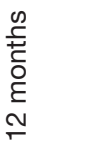

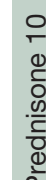

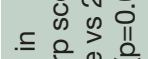

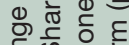

का की

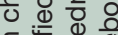

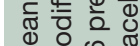

$\sum$ E웅
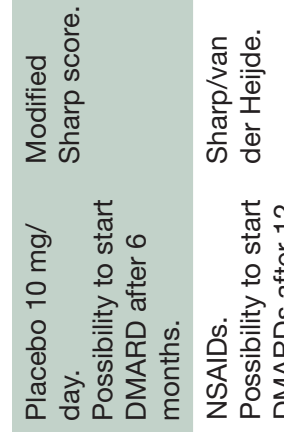

일 을

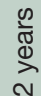

$\frac{\sqrt{1}}{\sqrt{+1}}$

$z \stackrel{\infty}{\sim}$

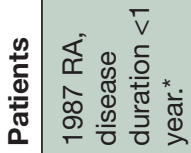

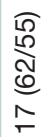

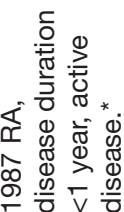

疍

$\stackrel{\infty}{\circ}$

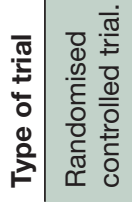

א

$\infty$

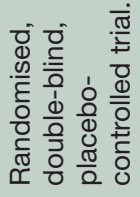

$\infty$

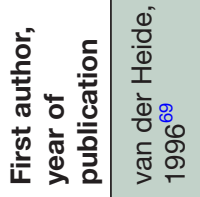
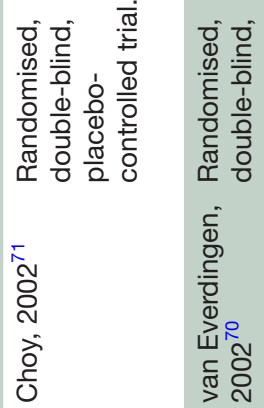

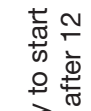

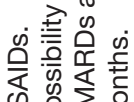

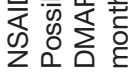

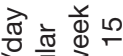

일

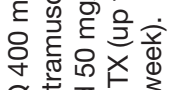

O․ㅡㄴ등

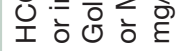

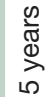

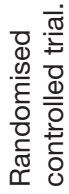

$\infty$

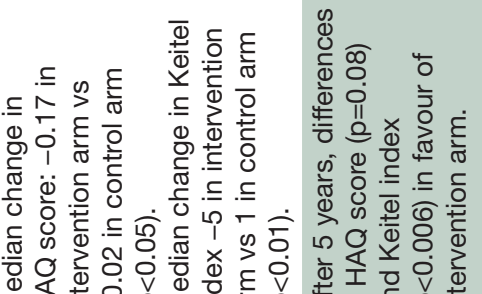

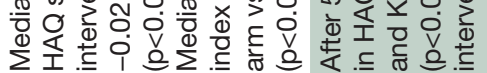

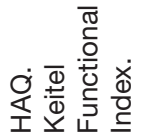

흥은

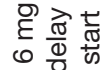

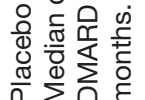

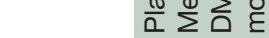

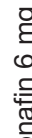

产

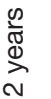

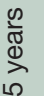

ชิ

魚

लํำ

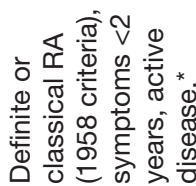

要要

흥 은

을

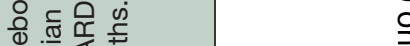

政

을 하항

फ్

용

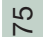

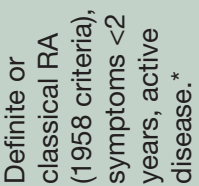

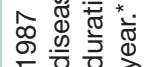

$\infty$

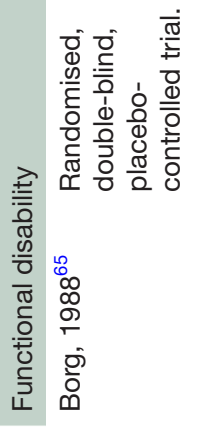

$\infty$

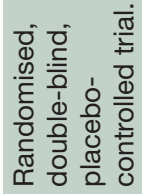

离, 


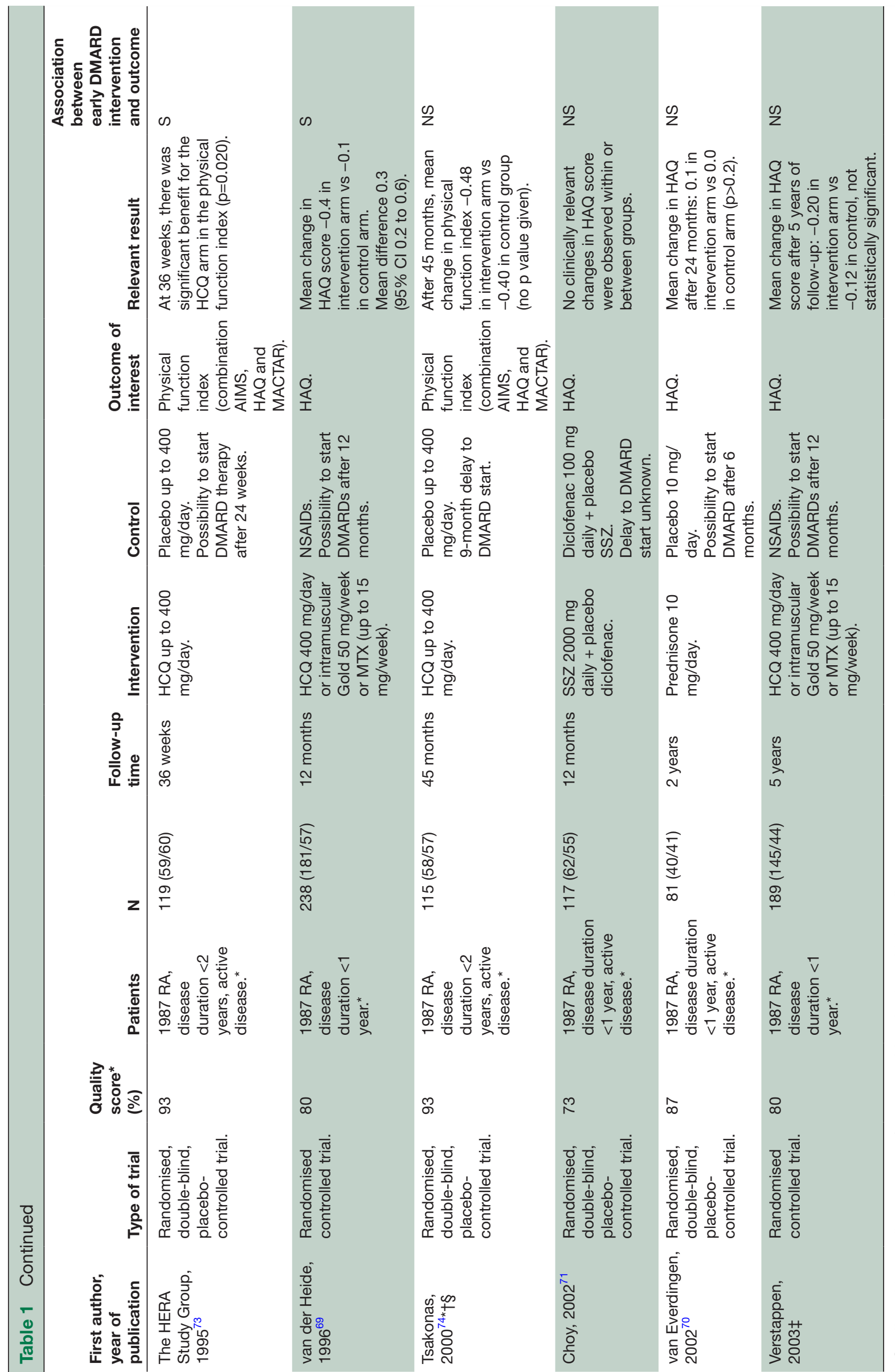

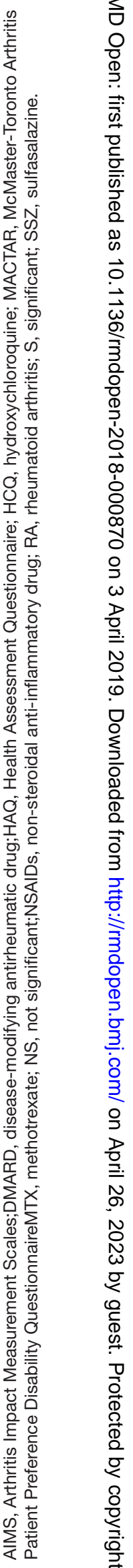




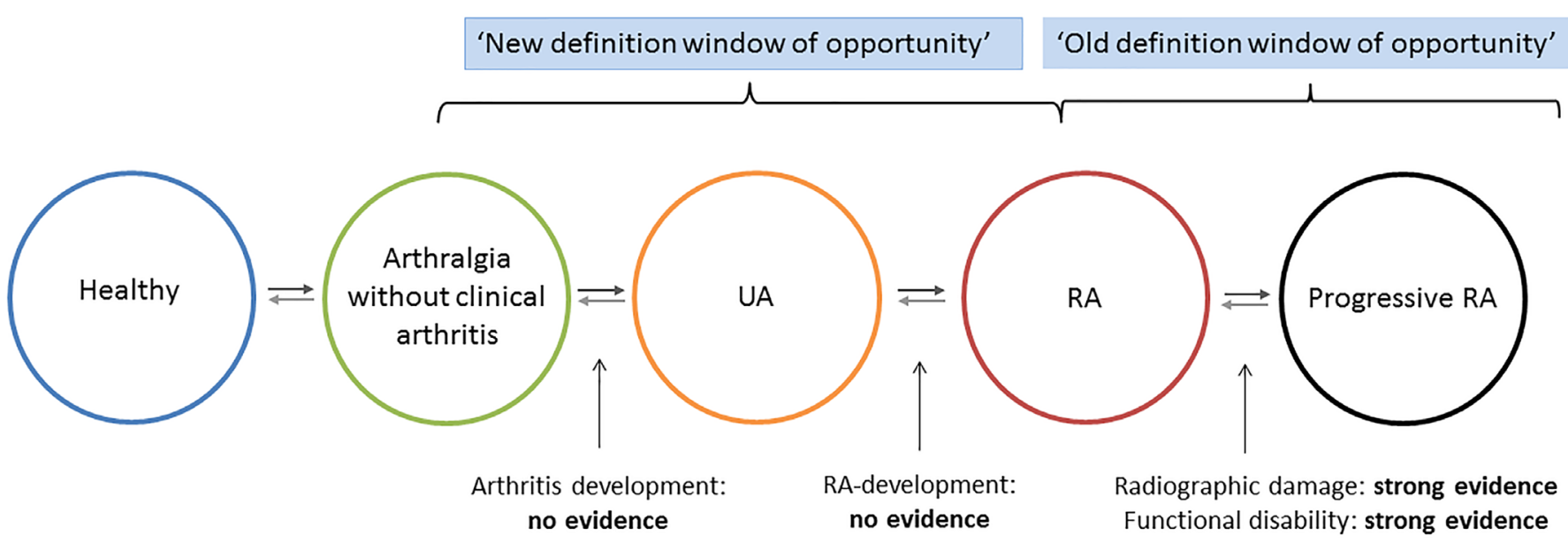

Figure 2 Summary of evidence for randomised controlled trials on the effect of early versus delayed treatment with diseasemodifying antirheumatic drugs per disease phase. RA, rheumatoid arthritis; UA, undifferentiated arthritis.

two reported on the same population. ${ }^{1765}$ Of the other three high-quality studies, two reported a non-significant benefit for early treatment. ${ }^{72} 74$ The early group started DMARDs 6-12 months earlier than the delayed group. Because of consistent findings in multiple high-quality RCTs, there is strong evidence for early DMARD initiation with regard to improved functional outcome (figure 2).

\section{RCTs in UA aiming to prevent RA development}

Next the literature was searched for RCTs in patients with UA (online supplementary methods). Six articles, reporting on five RCTs, compared DMARD treatment with placebo treatment in patients with UA (table 2). Different definitions of UA and inclusion criteria were used (table 2). Follow-up durations ranged between 1 and 5 years, and different DMARDs were investigated (MTX, infliximab, methylprednisolone and abatacept). The outcome was RA according to the 1987 criteria for $\mathrm{RA}^{75-78}$ or the clinical diagnosis. ${ }^{70}$ Four RCTs were of high quality. ${ }^{767798}$ None of the trials reached a significant difference in the primary outcome, but all four high-quality studies showed a tendency towards less RA development in the DMARD arm. Interestingly a recent meta-analysis of trials in patients with UA or very early RA by Hilliquin $e t a l^{81}$ did show a significant risk reduction on RA development in the case of DMARD initiation in a pre-RA phase when all trials were combined in one analysis. ${ }^{81}$ Nonetheless there is no conclusive evidence from individual RCTs that early treatment in patients with UA prevents progression to RA as none of the individual trials revealed a significant reduction (figure 2).

A difficult issue here is that the outcome in the trials was mostly fulfilment of the 1987 criteria, and that the concept of RA, at least with respect to classification, has changed in the last decennium. ${ }^{82}$ Some of the patients previously considered as UA may currently be diagnosed or classified as RA. On the other hand, patients with UA with a low risk of RA were also included. As demonstrated recently, such non-informative inclusions diminish the power to detect differences ${ }^{83}$ and may also have contributed to negative results.

Hopefully, a well-powered, placebo-controlled trial will be done in the nearby future to determine conclusively that early DMARD treatment in UA is beneficial in preventing progression to RA.

\section{RCTs in arthralgia without clinical arthritis aiming to prevent} RA development

Finally the literature was searched for RCTs (described in full papers) performed in patients considered at risk for RA development but without arthritis (online supplementary methods). One RCT was identified that included seropositive patients with arthralgia who were shared epitope-positive (table 3) ${ }^{84}$ Patients were randomised to either dexamethasone or placebo and followed for a median of 26 months. After this period, there was no difference in arthritis development between the two arms. Thus, no evidence from RCTs yet exists for prevention of arthritis by initiating DMARD treatment in patients with arthralgia without clinical arthritis with regard to arthritis/RA development (figure 2). However, several randomised clinical trials are currently ongoing and results are awaited in the next 5 years. ${ }^{7}$

\section{DISCUSSION AND FUTURE PERSPECTIVES}

The term 'window of opportunity' is commonly used within the field of RA, although its definition has changed over the last 25 years. There is an 'old definition' indicating that the therapeutic window lies within the first 2 years after disease onset, and treatment within it results in less radiographic damage and disability. We have here demonstrated that there is convincing evidence for this effect based on data from RCTs, particularly when treatment was delayed for 6-12 months after diagnosis, due to the use of placebo medication during this period. Notably, earlier treatment resulted in absolute lower levels of radiographic joint destruction and in slower progression rates. Lower absolute levels were possibly 


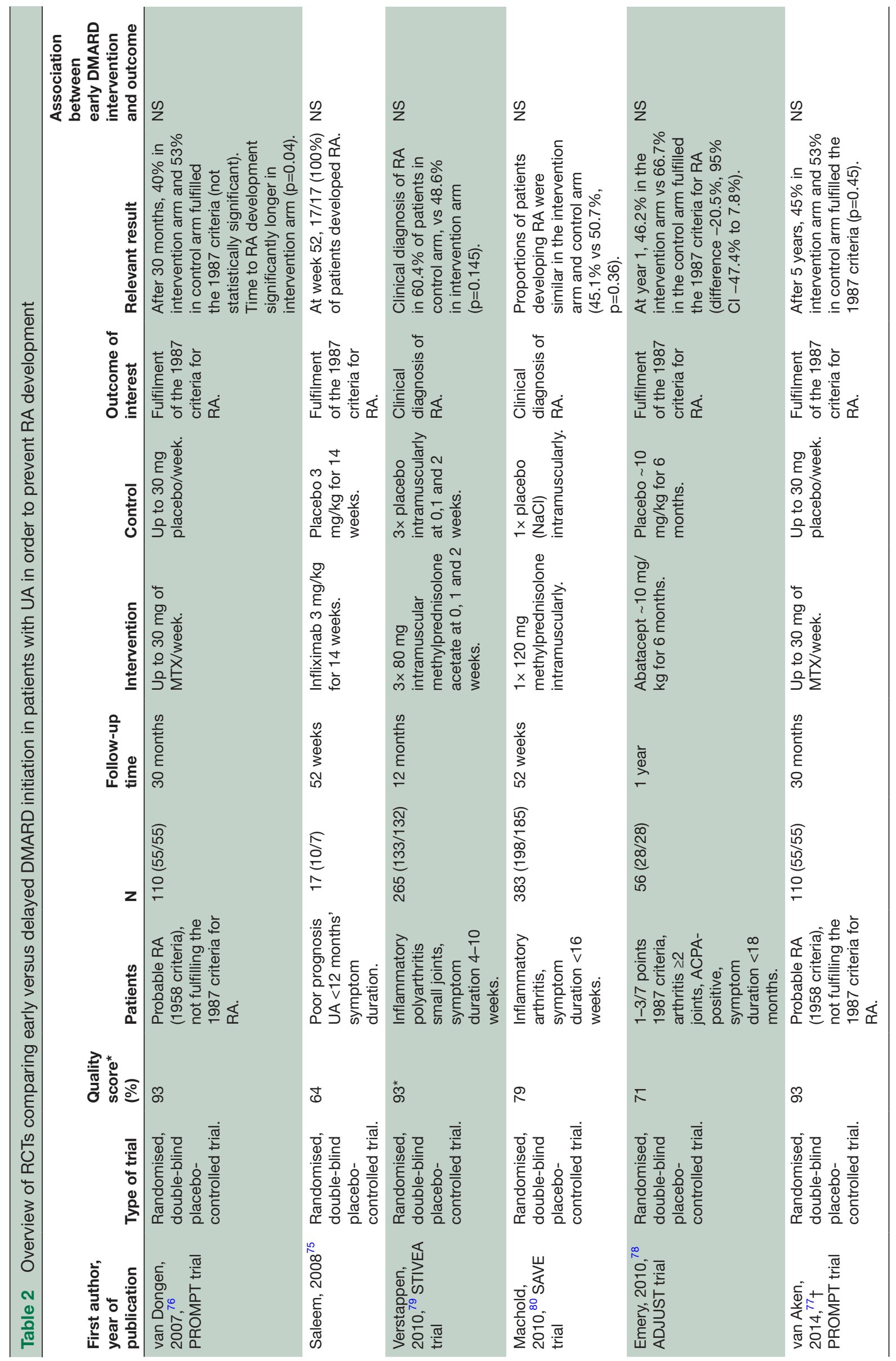

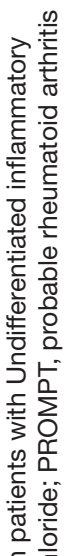

은

突旁

을 $\mathrm{Z}$.

엉

है

这

은

क

응 뭉

का एक

过券

일

동 응

๘ $\varepsilon$

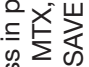

क्ष.

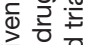

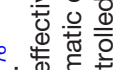

ब。

ब作

Ф).

ळ்

훅

की

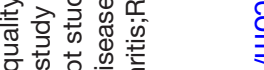

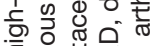

을 은

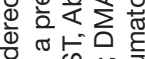

क응 00

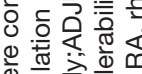

3 응웅ㅇㅇㅇ

ㅇํㅇ을 을

N

屯

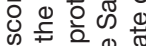

入ᄃ웡

중 $\pi$

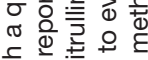

글을 훌

क मे क 0

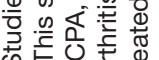

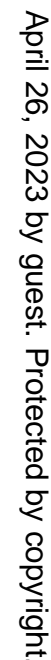




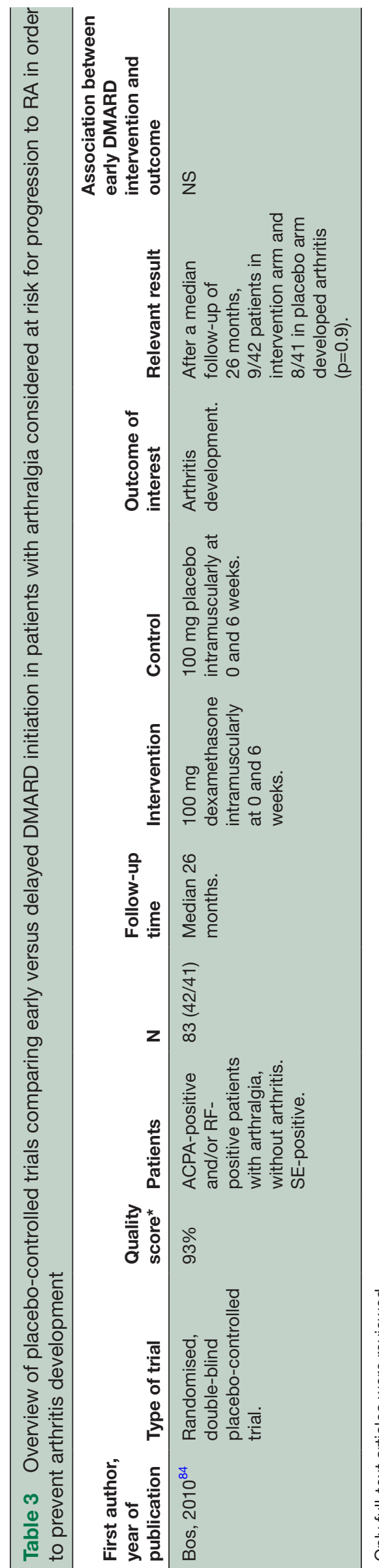

only the consequence of an earlier start, whereas a less steep rise in joint destruction is suggestive for true disease modification. In addition to an 'old definition', a 'new definition' is used in the literature as well. This states that the window could even lie in a phase preceding diagnosis or fulfilment of classification criteria for RA and that treatment initiated could possibly result in prevention of RA. However, this definition is not (yet) supported by evidence from RCTs.

Interpreting data from studies addressing the concept of a window of opportunity is challenging. One particular issue relates to understanding its duration. Measuring the duration of the window requires that a starting point is clearly defined. Many studies exploring the concept of a window of opportunity will simply report 'disease duration' and will conclude that treating patients with a disease duration of less than $x$ months is associated with improved outcomes compared with treating patients with disease duration of greater than $x$ months. However, when that $x$ months is timed from is often inadequately described. Possibilities include when the patient first developed (1) inflammatory-type joint symptoms, (2) patient-reported joint swelling, (3) physician-observed joint swelling and (4) physician-documented fulfilment of the RA classification criteria. ${ }^{85}$ Clearly adopting different definitions of a starting point for the disease onset will lead to different durations of the therapeutic window. ${ }^{21}$ Although some recall bias may be present when collecting information about starting points, especially when this was a long time ago, specifying the different starting points using uniform definitions will promote comparability between studies and the interpretation of findings.

Another issue relates whether the concept of a window of opportunity requires that there must be a time after which it closes, that is, a time after which intervention is not as effective as it was if used during the window. Trials have used placebo regimens for defined periods of time, but the rationale for the duration of placebo treatment is never discussed. Many observational studies dichotomised symptom duration and compared outcomes; here a cut-off was frequently placed at 3 months after symptom onset. However this choice actually refers back to two observational studies revealing that treatment initiation within 3 months after symptom onset was associated with less damage and more remission; evidence for the choice of this time period was not provided and other time periods were not explored. ${ }^{31} 86$ Thus far only one study evaluated the time course and provided suggestive evidence that a confined period in which treatment is more effective is more likely than a general 'the earlier the better' effect. ${ }^{19}$

In the first part of this Viewpoint, we assessed the most commonly used definitions of the window of opportunity. A limitation is that this was done by a literature search in one database. We presume that a search in more databases and also incorporating different terminology may have yielded some additional papers providing descriptions of the window of opportunity. However, we expect 
that a more systematic search will not result in different conclusions regarding the long-term disease outcomes and time periods most frequently mentioned in the different time periods (as presented in figure 1). In the second part in contrast, we determined the level of evidence. Here a systematic literature search of results obtained from RCTs was required. Due to heterogeneity in study designs, meta-analyses were not possible, but a best-evidence synthesis, based on the method described by the Cochrane Collaboration Back Review Group, was performed.

The present review of the literature demonstrated that different definitions of the window of opportunity are used, of which two definitions were common. It is clarifying if subsequent studies that use the term the window of opportunity will specify which definition is meant. The current work does neither allow to make a statement about the best definition of the window of opportunity, nor determine the optimal period for starting disease-modifying antirheumatic treatment. This is subject for future studies.

\section{CONCLUSION}

In summary, while the concept of a window of opportunity in RA is widely used, different definitions of this window exist. We propose to differentiate an 'old' and a 'new definition'. The 'old definition' points to the first 1-2 years after diagnosis with increased potential for disease-modifying treatment to prevent severe radiographic damage and disability, whereas the "new definition' presumes a therapeutic window in a pre-RA phase in which the biologic processes could be halted and RA development prevented by very early treatment. A review of RCTs revealed a high level of evidence for the 'old definition' but no scientific evidence for the 'new definition'. As there were relatively few trials performed in pre-RA phases, more research is needed to verify the new definition. Furthermore, to arrive at an evidence-based new definition of the window of opportunity, including information on its duration and possible closing, future trials should use adequately described definitions of the starting point.

Acknowledgements The authors thank JW Schoones of the Walaeus Library for his help with the literature search.

Contributors LEB did the literature search. All authors have written the manuscript and consented to the final version.

Funding This work has received funding from the European Research Council (ERC) under the European Union's Horizon 2020 research and innovation programme (starting grant, agreement no 714312). KR is supported by the NIHR Birmingham Biomedical Research Centre.

Competing interests None declared.

Patient consent for publication Not required.

Provenance and peer review Commissioned; externally peer reviewed.

Data sharing statement No primary data were collected in this manuscript, therefore the authors have no data to share.

Open access This is an open access article distributed in accordance with the Creative Commons Attribution Non Commercial (CC BY-NC 4.0) license, which permits others to distribute, remix, adapt, build upon this work non-commercially, and license their derivative works on different terms, provided the original work is properly cited, appropriate credit is given, any changes made indicated, and the use is non-commercial. See: http://creativecommons.org/licenses/by-nc/4.0/.

\section{REFERENCES}

1. van Nies JAB, Tsonaka R, Gaujoux-Viala C, et al. Evaluating relationships between symptom duration and persistence of rheumatoid arthritis: does a window of opportunity exist? results on the Leiden early arthritis clinic and ESPOIR cohorts. Ann Rheum Dis 2015;74:806-12.

2. Boers M. Understanding the window of opportunity concept in early rheumatoid arthritis. Arthritis Rheum 2003;48:1771-4.

3. Dawes PT, Symmons DPM. Short-term effects of antirheumatic drugs. Baillière's Clin Rheumatol 1992;6:117-40.

4. van Nies JAB, Krabben A, Schoones JW, et al. What is the evidence for the presence of a therapeutic window of opportunity in rheumatoid arthritis? A systematic literature review. Ann Rheum Dis 2014:73:861-70

5. Á S, Á H, Gulyás K, et al. Effects of targeted therapies on the bone in arthritides. Autoimmun Rev 2017;16:313-20.

6. Quinn MA, Cox S. The evidence for early intervention. Rheum Dis Clin North Am 2005;31:575-89.

7. van Steenbergen HW, da Silva JAP, Huizinga TWJ, et al. Preventing progression from arthralgia to arthritis: targeting the right patients. Nat Rev Rheumatol 2017 https://www.nature.com/articles/nrrheum. 2017.185 (cited 2017 Dec 18).

8. Lopez-Olivo MA, Kakpovbia-Eshareturi V, des Bordes J, et al. Treating early undifferentiated arthritis: a systematic review and meta-analysis of direct and indirect trial evidence. Arthritis Care Res 2017.

9. Mankia K, Emery P. A new window of opportunity in rheumatoid arthritis: targeting at-risk individuals. Curr Opin Rheumatol 2016;28:260-6.

10. Nam JL, Emery P. Is there a place for initial treatment with biological DMARDs in the early phase of RA? Best Practice \& Research Clinical Rheumatology 2013;27:537-54.

11. Goronzy JJ, Weyand CM. Developments in the scientific understanding of rheumatoid arthritis. Arthritis Res Ther 2009;11.

12. González-Álvaro I, Ortiz AM, Seoane IV, et al. Biomarkers predicting a need for intensive treatment in patients with early arthritis. Curr Pharm Des 2014;21:170-81

13. Keystone EC, van der Heijde D, Kavanaugh A, et al. Clinical, functional, and radiographic benefits of longterm adalimumab plus methotrexate: final 10-year data in longstanding rheumatoid arthritis. J Rheumatol 2013;40:1487-97.

14. Atzeni F, Sarzi-Puttini P. Early rheumatoid arthritis]. Reumatismo 2007;59:100-17.

15. Keen HI, Emery P. How should we manage early rheumatoid arthritis? from imaging to intervention. Curr Opin Rheumatol 2005;17:280-5

16. Bijlsma JW, Jacobs JW. The practice guideline "Rheumatoid arthritis" (first revision) from the Dutch College of General Practitioners: a response from the perspective of rheumatology]. Ned Tijdschr Geneeskd 2004;148:557-8

17. Egsmose C, Lund B, Borg G, et al. Patients with rheumatoid arthritis benefit from early 2nd line therapy: 5 year followup of a prospective double blind placebo controlled study. J Rheumatol 1995;22:2208-13.

18. Monti S, Montecucco C, Bugatti S, et al. Rheumatoid arthritis treatment: the earlier the better to prevent joint damage. RMD Open 2015;1(Suppl 1):e000057.

19. Nagy G, van Vollenhoven RF. Sustained biologic-free and drug-free remission in rheumatoid arthritis, where are we now? Arthritis Res Ther 2015;17.

20. Raza K, Filer A. The therapeutic window of opportunity in rheumatoid arthritis: does it ever close? Ann Rheum Dis 2015;74:793-4.

21. Raza K, Saber TP, Kvien TK, et al. Timing the therapeutic window of opportunity in early rheumatoid arthritis: proposal for definitions of disease duration in clinical trials. Ann Rheum Dis 2012;71:1921-3.

22. Gremese E, Salaffi F, Bosello SL, et al. Very early rheumatoid arthritis as a predictor of remission: a multicentre real life prospective study. Ann Rheum Dis 2013;72:858-62.

23. Jacobs JWG. Optimal use of non-biologic therapy in the treatment of rheumatoid arthritis. Rheumatology 2012;51(suppl 4):iv3-8.

24. van der Helm-van Mil AHM, Posthumus MD. Early recognition of rheumatoid arthritis]. Ned Tijdschr Geneeskd 2011;155.

25. Söderlin MK, Bergman S. Absent "Window of Opportunity" in smokers with short disease duration. Data from BARFOT, 
a multicenter study of early rheumatoid arthritis. $J$ Rheumatol $2011 ; 38: 2160-8$

26. Willemze A, van der Linden MPM, le Cessie S, et al. The window of opportunity in ACPA-positive rheumatoid arthritis is not explained by AcpA characteristics. Annals of the Rheumatic Diseases 2011;70:1697-8

27. Jack C, Hazel E, Bernatsky S. Something's missing here: a look at the quality of rheumatology referral letters. Rheumatol Int 2012;32:1083-5.

28. da MLMH, Laurindo IMM. Santos Neto LL dos. [Early rheumatoid arthritis: concepts]. Rev Assoc Medica Bras 1992 2010;56:227-9.

29. Raza K, Buckley CE, Salmon M, et al. Treating very early rheumatoid arthritis. Best Pract Res Clin Rheumatol 2006;20:849-63.

30. Smolen JS, Aletaha D, Machold KP. Therapeutic strategies in early rheumatoid arthritis. Best Pract Res Clin Rheumatol 2005;19:163-77.

31. Nell VPK, Machold KP, Eberl G, et al. Benefit of very early referral and very early therapy with disease-modifying anti-rheumatic drugs in patients with early rheumatoid arthritis. Rheumatology 2004:43:906-14.

32. Forien M, Ottaviani S. Ultrasound and follow-up of rheumatoid arthritis. Joint Bone Spine 2017;84:531-6.

33. Harrold LR, Litman HJ, Connolly SE, et al. A window of opportunity for abatacept in RA: is disease duration an independent predictor of low disease activity/remission in clinical practice? Clin Rheumatol 2017;36:1215-20

34. De Cock D, Van der Elst K, Meyfroidt S, et al. The optimal combination therapy for the treatment of early rheumatoid arthritis. Expert Opin Pharmacother 2015;16:1615-25.

35. Robinson PC, Brown MA. The window of opportunity: a relevant concept for axial spondyloarthritis. Arthritis Res Ther 2014;16.

36. Hwang YG, Moreland LW. Induction therapy with combination TNF inhibitor and methotrexate in early rheumatoid arthritis. Curr Rheumatol Rep 2014;16.

37. Kyburz D, Finckh $A$. The importance of early treatment for the prognosis of rheumatoid arthritis. Swiss Med Wkly 2013;143.

38. Breedveld $F$. The value of early intervention in RA-a window of opportunity. Clin Rheumatol 2011;30:33-9.

39. Kyburz D, Gabay C, Michel BA, et al. The long-term impact of early treatment of rheumatoid arthritis on radiographic progression: a population-based cohort study. Rheumatology 2011;50:1106-10.

40. Ngian G-S. Rheumatoid arthritis. Aust Fam Physician 2010;39:626-8.

41. Klarenbeek NB, Allaart CF, Kerstens PJSM, et al. The best story: on strategy trials in rheumatoid arthritis. Current Opinion in Rheumatology 2009;21:291-8.

42. Massardo L. Early rheumatoid arthritis]. Rev Med Chil 2008;136:1468-75.

43. Nurmohamed MT, Dijkmans BAC. Are biologics more effective than classical disease-modifying antirheumatic drugs? Arthritis Res Ther 2008;10.

44. Valesini G, Di Franco M, Spinelli FR, et al. Induction of remission in rheumatoid arthritis: criteria and opportunities. Rheumatol Int 2008;29:131-9.

45. Sherrer Y. Abatacept in biologic-naïve patients and TNF inadequate responders: clinical data in focus. Curr Med Res Opin 2008;24:2283-94

46. Cush JJ. Early rheumatoid arthritis - is there a window of opportunity? J Rheumatol Suppl 2007;80:1-7.

47. Choy EHS, Smith CM, Farewell V, et al. Factorial randomised controlled trial of glucocorticoids and combination disease modifying drugs in early rheumatoid arthritis. Ann Rheum Dis 2008;67:656-63.

48. Fukuda T. Window of opportunity for treatment of rheumatoid arthritis]. Nihon Rinsho Jpn J Clin Med 2007;65:1276-81.

49. Yamaguchi Y, Yamamoto K. New therapeutic strategy of rheumatoid arthritis to reach the goal of suppression of joint destruction]. Clin Calcium 2007:17:463-73.

50. Finckh $\mathrm{A}$, Liang $\mathrm{MH}$, van Herckenrode $\mathrm{CM}$, et al. Long-term impact of early treatment on radiographic progression in rheumatoid arthritis: a meta-analysis. Arthritis Rheum 2006;55:864-72.

51. Finckh A, Gabay C, Guerne P-A. Review of the protective effects of tumor necrosis factor inhibitors in rheumatoid arthritis]. Rev Med Suisse Romande 2004;124:547-50.

52. Quinn MA, Emery P. Window of opportunity in early rheumatoid arthritis: possibility of altering the disease process with early intervention. Clin Exp Rheumatol 2003;21(5 Suppl 31):S154-7.

53. Bresnihan B. Are synovial biopsies of diagnostic value? Arthritis Res Ther 2003;5:271-8.

54. Geletka R, St Clair EW. Treatment of early rheumatoid arthritis. Best Pract Res Clin Rheumatol 2003;17:791-809.
55. Espinoza F, Fabre S, Pers Y-M. Remission-induction therapies for early rheumatoid arthritis: evidence to date and clinical implications. Therapeutic Advances in Musculoskeletal 2016;8:107-18.

56. Contreras-Yáñez I, Pascual-Ramos V. Window of opportunity to achieve major outcomes in early rheumatoid arthritis patients: how persistence with therapy matters. Arthritis Res Ther 2015;17.

57. Her M, Kavanaugh A. Advances in use of immunomodulatory agents - a rheumatology perspective. Nat Rev Gastroenterol Hepatol 2015;12:363-8.

58. Greisen SR, Schelde KK, Rasmussen TK, et al. CXCL13 predicts disease activity in early rheumatoid arthritis and could be an indicator of the therapeutic 'window of opportunity'. Arthritis Res Ther 2014;16.

59. Resman-Targoff BH, Cicero MP. Aggressive treatment of early rheumatoid arthritis: recognizing the window of opportunity and treating to target goals. Am J Manag Care 2010;16(9 Suppl):S249-58.

60. Thomas D. Management of patients with rheumatoid arthritis]. Ther Umsch Rev Ther 2005;62:281-4.

61. Furst DE. Window of opportunity. J Rheumatol 2004;31:1677-9.

62. Quinn MA, Emery P. Potential for altering rheumatoid arthritis outcome. Rheum Dis Clin North Am 2005;31:763-72.

63. Kwok WY, Plevier JWM, Rosendaal FR, et al. Risk factors for progression in hand osteoarthritis: a systematic review. Arthritis Care Res 2013;65:552-62.

64. van Tulder M, Furlan A, Bombardier C, et al. Updated method guidelines for systematic reviews in the Cochrane collaboration back review group. Spine 2003;28:1290-9.

65. Borg G, Allander E, Lund B, et al. Auranofin improves outcome in early rheumatoid arthritis. Results from a 2-year, double blind placebo controlled study. J Rheumatol 1988;15:1747-54.

66. Sulfasalazine in early rheumatoid arthritis. The Australian multicentre clinical Trial Group. J Rheumatol 1992;19:1672-7.

67. Hannonen P, Möttönen T, Hakola M, et al. Sulfasalazine in early rheumatoid arthritis. a 48-week double-blind, prospective, placebocontrolled study. Arthritis \& Rheumatism 1993;36:1501-9.

68. Buckland-Wright JC, Clarke GS, Chikanza IC, et al. Quantitative microfocal radiography detects changes in erosion area in patients with early rheumatoid arthritis treated with myocrisine. J Rheumatol 1993;20:243-7.

69. van der Heide A, Jacobs JW, Bijlsma JW, et al. The effectiveness of early treatment with "second-line" antirheumatic drugs. A randomized, controlled trial. Ann Intern Med 1996;124:699-707.

70. van Everdingen AA, Jacobs JWG, Siewertsz van Reesema DR, et al. Low-dose prednisone therapy for patients with early active rheumatoid arthritis: Clinical efficacy, disease-modifying properties, and side effects: a randomized, double-blind, placebo-controlled clinical trial. Ann Intern Med 2002;136.

71. Choy EHS, Scott DL, Kingsley GH, et al. Treating rheumatoid arthritis early with disease modifying drugs reduces joint damage: a randomised double blind trial of sulphasalazine vs diclofenac sodium. Clin Exp Rheumatol 2002;20:351-8.

72. Verstappen SMM, Jacobs JWG, Bijlsma JWJ, et al. Five-year followup of rheumatoid arthritis patients after early treatment with disease-modifying antirheumatic drugs versus treatment according to the pyramid approach in the first year. Arthritis \& Rheumatism 2003;48:1797-807.

73. A randomized trial of hydroxychloroquine in early rheumatoid arthritis: the HERA study. Am J Med 1995;98:156-68.

74. Tsakonas E, Fitzgerald AA, Fitzcharles MA, et al. Consequences of delayed therapy with second-line agents in rheumatoid arthritis: a 3 year followup on the hydroxychloroquine in early rheumatoid arthritis (HERA) study. J Rheumatol 2000;27:623-9.

75. Saleem B, Mackie S, Quinn M, et al. Does the use of tumour necrosis factor antagonist therapy in poor prognosis, undifferentiated arthritis prevent progression to rheumatoid arthritis? Ann Rheum Dis 2008:67:1178-80.

76. van Dongen $\mathrm{H}$, van Aken J, Lard LR, et al. Efficacy of methotrexate treatment in patients with probable rheumatoid arthritis: a doubleblind, randomized, placebo-controlled trial. Arthritis Rheum 2007;56:1424-32.

77. van Aken J, Heimans L, Gillet-van Dongen $\mathrm{H}$, et al. Five-year outcomes of probable rheumatoid arthritis treated with methotrexate or placebo during the first year (the prompt study). Ann Rheum Dis 2014;73:396-400.

78. Emery P, Durez P, Dougados M, et al. Impact of T-cell costimulation modulation in patients with undifferentiated inflammatory arthritis or very early rheumatoid arthritis: a clinical and imaging study of abatacept (the adjust trial). Annals of the Rheumatic Diseases 2010;69:510-6. 
79. Verstappen SMM, McCoy MJ, Roberts C, et al. Beneficial effects of a 3-week course of intramuscular glucocorticoid injections in patients with very early inflammatory polyarthritis: results of the STIVEA trial. Annals of the Rheumatic Diseases 2010;69:503-9.

80. Machold KP, Landewé R, Smolen JS, et al. The stop arthritis very early (save) trial, an international multicentre, randomised, doubleblind, placebo-controlled trial on glucocorticoids in very early arthritis. Annals of the Rheumatic Diseases 2010;69:495-502.

81. Hilliquin S, Hugues B, Mitrovic S, et al. Ability of disease-modifying antirheumatic drugs to prevent or delay rheumatoid arthritis onset: a systematic literature review and meta-analysis. Ann Rheum Dis 2018;77:1099-106.

82. van der Helm-van Mil AHM, Zink A. What is rheumatoid arthritis? Considering consequences of changed classification criteria. Ann Rheum Dis 2016.
83. Burgers LE, Allaart CF, Huizinga TWJ, et al. Brief Report: Clinical Trials Aiming to Prevent Rheumatoid Arthritis Cannot Detect Prevention Without Adequate Risk Stratification: A Trial of Methotrexate Versus Placebo in Undifferentiated Arthritis as an Example. Arthritis \& Rheumatology 2017;69:926-31.

84. Bos WH, Dijkmans BAC, Boers M, et al. Effect of dexamethasone on autoantibody levels and arthritis development in patients with arthralgia: a randomised trial. Annals of the Rheumatic Diseases 2010;69:571-4.

85. Stack RJ, Sahni M, Mallen CD, et al. Symptom complexes at the earliest phases of rheumatoid arthritis: a synthesis of the qualitative literature. Arthritis \& Rheumatism 2013;65:1916-26.

86. van der Linden MPM, le Cessie S, Raza K, et al. Long-term impact of delay in assessment of patients with early arthritis. Arthritis \& Rheumatism 2010;62:3537-46. 